\title{
NOVEL GENTAYANGAN PILIH SENDIRI PETUALANGAN SEPATU MERAHMU KARYA INTAN PARAMADITHA SEBAGAI ALTERNATIF BAHAN AJAR SASTRA DI SMA KELAS XII
}

\author{
Anis Surya Trisanti \\ Pendidikan Bahasa dan Sastra Indonesia, Fakultas Keguruan dan Ilmu \\ Pendidikan, Universitas Ahmad Dahlan \\ anissuryatrisanti@gmail.com
}

\begin{abstract}
ABSTRAK
Novel Gentayangan Pilih Sendiri Petualangan Sepatu Merahmu karya Intan Paramaditha merupakan novel yang menarik. Novel tersebut memiliki beberapa tokoh, tiga alur cerita, dan latar sehingga membuat cerita seakan nyata. Penelitian ini bertujuan untuk mendeskripsikan kesesuaikan novel Gentayangan Pilih Sendiri Petualangan Sepatu Merahmu karya Intan Paramaditha sebagai bahan ajar sastra di SMA. Penelitian ini menggunakan metode deskriptif kualitatif. Sumber data dalam penelitian ini adalah novel Gentayangan Pilih Sendiri Petualangan Sepatu Merahmu karya Intan Paramaditha yang diterbitkan pada tahun 2017. Data yang digunakan dalam penelitian ini berupa kesesuaikan novel Gentayangan Pilih Sendiri Petualangan Sepatu Merahmu karya Intan Paramaditha sebagai alternatif bahan ajar sastra di SMA. Hasil penelitian menunjukan bahwa novel Gentayangan Pilih Sendiri Petualangan Sepatu Merahmu karya Intan Paramaditha dapat di jadikan sebagai alternatif bahan ajar sastra di SMA kelas XII karena sesuai dengan Kompetensi Dasar (KD) 3.9 menganalisis isi dan kebahasaan novel dan 4.9 merancang novel atau novelet dengan memerhatikan isi dan kebahasaan.
\end{abstract}

Kata kunci: novel Gentayangan Pilih Sendiri Petualangan Sepatu Merahmu, Intan Paramaditha, bahan ajar

\section{PENDAHULUAN}

Karya sastra perlu diperkenalkan kepada siswa sesuai dengan tujuan pembelajarannya. Siswa mampu menghargai, menghayati, memahami serta dapat menemukan nilai luhur yang ada pada karya sastra merupakan tujuan umum dari pembelajaran sastra. Selain itu pembelajaran sastra bertujuan agar siswa mendapat pengalaman mengekspresi dan mengapresiasikan hasil karya sastra. Menurut Nurgiyantoro (2013:29) sebuah novel merupakan sebuah totalitas, suatu kemenyeluruhan yang bersifat artistik. Oleh karena itu di dalam sebuah novel terdapat unsur yang saling berkaitan. Sebuah novel dikatakan totalitas karena kata dan bahasa menjadi salah satu bagian dari totalitas itu.

Sebagai karya fiksi, novel menawarkan sebuah dunia yang berisi kehidupan yang diidealkan dan dunia imajinatif. Kehidupan yang ideal yaitu kehidupan yang harmonis antara jasmani dan rohani. Sebuah cerita yang dirangkai dalam berbagai peristiwa yang saling berkaitan dan menampilkan peristiwa yang dialami tokoh utamanya, sehingga dapat menyebabkan perubahan dalam sikap hidupnya disebut novel. Unsur intrinsik yang terdapat dalam novel yaitu peristiwa, plot, tokoh, penokohan, latar, dan sudut pandang. 
Novel Gentayangan Pilih Sendiri Petualangan Sepatu Merahmu karya Intan Paramaditha bisa digunakan sebagai bahan ajar sastra dari segi sudut pandang bahasa, psikologi, dan ditinjau dari latar belakang budaya. Menurut Rahmanto (2004:27) bahasa, psikologi, dan latar belakang kebudayaan peserta didik menjadi aspek penting yang harus ada ketika melakukan pemilihan bahan ajar sastra. Berdasarkan kriteria pemilihan bahan ajar sastra tersebut, dapat diterapkan melalui novel Genyatangan Pilih Sendiri Petualangan Sepatu Merahmu karya Intan Paramaditha

Novel Gentayangan Pilih Sendiri Petualangan Sepatu Merahmu karya Intan Paramaditha merupakan novel imajinasi. Kata "gentayangan" yang terdapat pada judul memberikan kesan sebuah novel misteri padahal novel tersebut menceritakan petualangan seorang perempuan dengan sepatu merahnya. Sepatu merah tersebut adalah sepatu merah terkutuk yang ia dapatkan dari kekasihnya yang berwujud Iblis. Selain itu novel berjudul Gentayangan Pilih Sendiri Petualangan Sepatu Merahmu karya Intan Paramaditha juga memiliki hubungan menarik untuk diteliti, yaitu hubungan antara karakter, alur, dan latar. Novel tersebut semakin menarik untuk dibahas karena memiliki unsur-unsur intrinsik yang menarik. Pada novel tersebut terdapat berbagai karakter, alur yang unik sehingga membuat pembaca ingin terus membaca peristiwa demi peristiwa, dan pendeskripsian latar yang disampaikan dengan baik.

Intan Paramaditha adalah seorang penulis yang berbakat. Pada tahun 2013 ia berhasil meraih penghargaan cerpen terbaik Kompas. Beberapa karyanya diterjemahkan ke dalam bahasa Inggris dan Jerman. Intan memiliki beberapa karya fiksi yaitu kumpulan cerpen Sihir Perempuan, nominasi pendek Khatulistiwa Literary Award 2005. Selain karya fiksi, ia juga memiliki kumpulan Budak Setan, proyek kumpulan cerita horor, serta naskah pertunjukan teater Goyang Penasaran (Teater Garasi, 2011-2013).

Kurikulum 2013 mata pelajaran Bahasa Indonesia menggunakan pendekatan genre-based, genre-pedagogy, dan content language integrated learning (CLIL) atau disebut pendekatan berbasis genre atau berbasis teks. Genre merupakan makna dan tujuan sosial, tipe teks adalah bentuk fisiknya. Teks merupakan perwujudan sosial dan bertujuan sosial, baik lisan maupun tulis, sehingga teks ini bukan diartikan sebagai tulisan berbentuk artikel.

Tujuan dari kurikulum 2013 revisi 2019 yaitu agar peserta didik mampu mendengarkan, membaca, memirsa, berbicara, dan menulis. Kompetensi dasar dikembangkan untuk pengetahuan siswa. Hal tersebut adalah bahasa (pengetahuan tentang Bahasa Indonesia); sastra (memahami, mengapresiasi, menanggapi, menganalisis, dan menciptakan karya sastra); literasi (memperluas kompetensi berbahasa Indonesia dalam berbagai tujuan khususnya yang berkaitan dengan membaca dan menulis).

Pemilihan bahan ajar pengajaran sastra sesuai dengan Silabus Mata Pelajaran Bahasa Indonisia SMA/MA/SMK/MAK Kelas XII, yang terdapat dalam Kurikulum 2013 revisi tahun 2019 dengan Kompetensi Inti 3 yaitu memahami, menerapkan, menganalisis dan mengevaluasi pengetahuan faktual, konseptual, prosedural, dan metakognitif berdasarkan rasa ingin tahunya tentang ilmu pengetahuan, teknologi, seni, budaya, dan humaniora dengan wawasan kemanusiaan, kebangsaan, kenegaraan, dan peradaban terkait penyebab fenomena dan kejadian, serta menerapkan pengetahuan prosedural pada bidang kajian yang 
spesifik sesuai dengan bakat dan minatnya untuk memecahkan masalah. Kompetensi dasar 3.9 yang berbunyi menganalisis isi dan kebahasaan noveldan 4.9 yang berbunyi merancang novel atau novelet dengan memerhatikan isi dan kebahasaan.

Penelitian ini akan dikaitkan dengan pengajaran yang akan disampaikan kepada peserta didik sebagai alternatif bahan ajar. Penulis sudah mempertimbangkan, bahwa novel Gentayangan Pilih Sendiri Petualangan Sepatu Merahmu karya Intan Paramadhita dapat digunakan sebagai pengajaran sastra di SMA dilihat dari segi bahasa, psikologi, dan latar belakang budaya. Selain itu, novel tersebut akan digunakan sebagai alternatif pengajaran sastra, karena bahan ajar sastra yang digunakan selama ini masih monoton atau terpaku pada novel-novel lama, sementara novel terus berkembang. Hal tersebut diharapkan dapat memberikan nilai-nilai positif bagi peserta didik. Penelitian ini akan disesuaikan dengan Kurikulum 2013 Revisi 2019 pada tingkat SMA, dengan melihat silabus mata pelajaran Bahasa Indonesia pengajaran sastra noveldi kelas XII dengan KI (Kompetensi Inti) 3 dan KD (Kompetensi Dasar) nomor 3. 9 dan nomor 4. 9.

\section{METODE PENELITIAN}

Jenis penelitian ini merupakan penelitian deskriptif kualitatif. Penelitian yang menggunakan metode kualitatif, penelitian yang digunakan bersifat deskriptif. Penelitian ini akan mendeskripsikan kesesuaian novel Gentayangan Pilih Sendiri Petualangan Sepatu Merahmu karya Intan Paramaditha sebagai alternatif bahan ajar sastra di SMA. Metode yang digunakan dalam penelitian ini yaitu metode simak. Peneliti akan menyimak novel Gentayangan Pilih Sendiri Petualangan Sepatu Merahmu karya Intan Paramaditha. Teknik pengumpulan data yang dilakukan yaitu teknik sadap dan catat. Teknik sadap digunakan sebagai teknik dasar dalam metode simak. Peneliti akan menyadap maksud dari novel Gentayangan Pilih Sendiri Petualangan Sepatu Merahmu karya Intan Paramaditha dengan cara membacanya. Peneliti akan membaca novel tersebut secara cermat. Teknik selanjutnya yang dilakukan adalah teknik catat untuk menuliskan data yang sudah ditemukan.

\section{HASIL DAN PEMBAHASAN}

Novel Gentayangan Pilih Sendiri Petualangan Sepatu Merahmu karya Intan Paramaditha dapat digunakan sebagai alternatif bahan ajarsastra di SMA karena telah memenuhi syarat konsep pemilihan bahan ajar di dalam kurikulum 2013 revisi 2019. Pemilihan bahan ajar sastra pada novel Gentayangan Pilih Sendiri Petualangan Sepatu Merahmu karya Intan Paramaditha, sebagai berikut.

\section{A. Hasil}

Hasil penelitian yang diperoleh berupa deskripsi mengenai kesesuaian novel Gentayangan Pilih Sendiri Petualangan Sepatu Merahmu karya Intan Paramaditha sebagai alternative bahan ajar sastra di SMA kelas XII.

a. Bahasa yang digunakan

Menurut Rahmanto (2004:27) bahasa memegang peranan penting dalam sebuah pembelajaran. Novel yang akan dijadikan sebagai bahan pengajaran sastra hendaknya dapat dipertanggungjawabkan dari segi bahasa. Novel tersebut harus menggunakan bahasa yang mudah dipahami. Selain itu, novel tersebutharus diseleksi terlebih dahulu sebelum diberikan kepada peserta didik. Novel 
Gentayangan Pilih Sendiri Petualangan Sepatu Merahmu karya Intan Paramaditha, merupakan novelsastra yang sesuai diberikan kepada peserta didik. Novel tersebut memiliki bahasa yang mudah dimengerti oleh peserta didik.

\section{b. Psikologi}

Menurut Rahmanto (2004:29) tahap perkembangan psikologi perlu diperhatikan karena tahap-tahap tersebut berpengaruh besar terhadap minat dan keengganan peserta didik dalam banyak hal. Novel Gentayangan Pilih Sendiri Petualangan Sepatu Merahmu karya Intan Paramaditha mengarah ke tahap perkembangan psikologi anak pada usia 16 tahun atau tahap generalisasi. Pada tahap tersebut, peserta didik sudah memiliki minat pada hal realistis dan dapat merumuskan penyebab utama fenomena yang terjadi dengan pemikirannya sendiri.

\section{c. Latar Belakang Budaya}

Menurut Rahmanto (2004:31) peserta didik akan tertarik pada karya sastra yang latar belakang ceritanya berhubungan dengan latar belakang kehidupan mereka. Novel yang akan dijadikan sebagai bahan ajar sebaiknya mengandung permasalahan dan persoalan nilai-nilai kehidupan. Hal tersebut bertujuan agar peserta didik dapat menemukan persoalan dan mencari solusi untuk menyelesaikannya. Pada novel Gentayangan Pilih Sendiri Petualangan Sepatu Merahmu karya Intan Paramadithaterdapat persoalan yang berkaitan dengan masalah kehidupan dan dapat dijelaskan mengenai cara untuk menyesaikan masalah tersebut.

Penggunaan novel sebagai alternatif bahan ajar sastra di SMA kelas XII akan dikaitkan sesuai dengan Kurikulum 2013 revisi 2019 dengan K. I 3, dan K.D nomor 3. 9 dan nomor 4. 9 .

K.I 3 Memahami, menerapkan, menganalisis dan mengevaluasi pengetahuan faktual, konseptual, prosedural, dan metakognitif berdasarkan rasa ingin tahunya tentang ilmu pengetahuan, teknologi, seni, budaya dan humaniora dengan wawasan kemanusiaan, kebangsaan, kenegaraan, dan peradaban terkait penyebab fenomena dan kejadian, serta menerapkan pengetahuan prosedural pada bidang kajian yang spesifik sesuai dengan bekat dan minatnya untuk memecahkan masalah.

Kompetensi Dasar

3.9 Menganalisis isi dan kebahasaan novel.

4.9 Merancang novelatau novelet dengan memerhatikan isi dan kebahasaan.

Tidak semua novel dapat dijadikan sebagai bahan ajar sastra di sekolah. Novel yang dapat dijadikan sebagai bahan ajar sastra harus memiliki pesan positif untuk peserta didik, agar peserta didik dapat menerapkannya di kehidupan seharihari dan menjadikan individu yang lebih baik.Hasil analisis tentang fakta cerita dalam novel Gentayangan Pilih Sendiri Petualangan Sepatu Merahmu karya Intan Paramaditha, selanjutnya akan digunakan sebagai alternatif bahan ajar sastra di SMA. Novel tersebut digunakan sebagai alternatif bahan ajar sastra di SMA karena telah memenuhi sayarat pada konsep pemilihan bahan ajar di dalam kurikulum 2013 revisi 2019.

Pemilihan bahan pengajaran sastra pada novel Gentayangan Pilih Sendiri Petualangan Sepatu Merahmu karya Intan Paramaditha menggunakan teori milik Rahmanto.Menurut Rahmanto (2004:27) bahasa, psikologi, dan latar belakang kebudayaan peserta didik merupakan aspek penting yang harus ada ketika melakukan pemilihan bahan ajar sastra. 


\section{B. Pembahasan}

\section{a. Ditinjau dari sudut Bahasa}

Novel yang akan dijadikan sebagai bahan ajar sastra hendaknya dapat dipertanggungjawabkan dari segi bahasa. Novel tersebut harus melalui seleksi terlebih dahulu. Bahasa yang digunakan dalam novel harus mudah dipahami. Novel Gentayangan Pilih Sendiri Petualangan Sepatu Merahmu karya Intan Paramaditha merupakan novelsastra yang sesuai untuk diberikan kepada peserta didik dilihat dari segi bahasanya. Hal tersebut dapat dilihat pada kutipan di bawah ini, sebagai berikut.

Kau duduk di kelas tiga SMA saat mahasiswa berdemonstrasi menuntut Suharto mundur. Gejolak politik membakar negerimu, sedangkan kau menghadapi gejolak yang lain. Orang tuamu bersiap pindah ke Jogja karena krisis moneter menyebabkan banyak pegawai diberhentikan, termasuk ayahmu. Kau tidak mau ikut mereka, maka kau belajar mati-matian agar dapat dterima di Universitas Indonesia (Paramaditha, 2017:14).

Berdasarkan uraian di atas, novel Gentayangan Pilih Sendiri Petualangan Sepatu Merahmu karya Intan Paramadithamempunyai kesesuaian dengan bahasa yang digunakan sehari-hari. Karakter pantang menyerah yang diperankan oleh tokoh Kau sesuai dengan karakter peserta didik SMA pada umumnya. Bahasa yang digunakan mudah dipahami, sehingga peserta didik menjadi lebih mudah memahami karakter tokoh Kau, peserta didik juga akan termotivasi untuk menerapkan karakter tersebut.

\section{b. Ditinjau dari Psikologi}

Novel Gentayangan Pilih Sendiri Petualangan Sepatu Merahmu karya Intan Paramaditha mengarah ke tahap perkembangan psikologi anak pada usia 16 tahun atau tahap generalisasi. Peserta didik dapat dengan mudah untuk menafsirkan makna-makna yang terdapat dalam novel dan sesuai untuk siswa SMA. Hal tersebut dapat dilihat pada kutipan di bawah ini, sebagai berikut.

Di hari pengumuman mahasiswa baru, kau tidak menemukan namamu di Koran. Ibu memelukmu erat. Banyak anak pintar gagal masuk UI, hiburnya. Kata-kata manis tak membuatmu merasa lebih baik. Beberapa teman, yang sepertinya tak lebih pintar darimu, lulus ujian masuk perguruan tinggi negeri. Hingga kini, jika kau mengingat kegagalnmu, kau sering mempertanyakan banyak hal. Apakah kau tidak berhato-hati mengerjakan soal? Apakah kertas ujianmu basah oleh keringat sehingga jawabanmu tidka terbaca? (Paramaditha, 2017:15).

Berdasarkan kutipan di atas menunjukkan bahwa novel Gentayangan Pilih Sendiri Petualangan Sepatu Merahmu karya Intan Paramadithamempunyai kesesuaian dengan usia peserta didik. Kutipan di atas mewakili kekecewaan siswa SMA yang tidak diterima di perguruan tinggi negeri. Kekecewaan terhadap kenyataan sangat terlihat pada kutipan tersebut.

"Yang paling memukul adalah kenyataan bahwa kakakmu saat itu mahasiswa Teknik Mesin Institut Teknologi Bandung, kampus terbaik seIndonesia dalam bidang sains." (Paramaditha, 2017:15).

Berdasarkan kutipan di atas, menunjukkan bahwa tokoh Kau merasakan kecewa pada dirinya sendiri. Ia tidak bisa diterima di perguruan tinggi negeri seperti kakaknya. Peristiwa yang dialami tokoh Kau merupakan sebuah peristiwa yang sering dialami oleh anak seusianya. Dengan demikian, novel Gentayangan Pilih 
Sendiri Petualangan Sepatu Merahmu karya Intan Paramadithamempunyai kesesuaian dengan usia peserta didik.

\section{c. Latar Belakang Budaya}

Novel Gentayangan Pilih Sendiri Petualangan Sepatu Merahmu karya Intan Paramaditha terdapat persoalan yang berkaitan dengan masalah hidup dan dapat dijelaskan bagaimana cara untuk dapat menyelesaikan masalah tersebut. Hal tersebut dapat dilihat pada kutipan di bawah ini, sebagai berikut.

Tiga hari telah lewat setelah jadwal kedatangan Bob. Kau menarik kesimpulan bahwa sesuatu yang tidak beres sedang terjadi. Suamimu hilang. Lenyap. Tidak ada kata lain yang lebih santun. Kau bergegas pergi ke kantor polisi (Paramaditha, 2017:337).

Berdasarkan uraian di atas, menunjukkan bahwa novel Gentayangan Pilih Sendiri Petualangan Sepatu Merahmu karya Intan Paramaditha mempunyai kesesuaian dengan lingkungan sosial. Tokoh Kau segera melapor ke kantor polisi setelah suaminya yang hilang tanpa kabar.

Berdasarkan uraian fakta cerita yang terdapat dalam novel Gentayangan Pilih Sendiri Petualangan Sepatu Merahmu karya Intan Paramaditha, layak dan sesuai dengan Kurikulum 2013 Revisi 2019 sesuai pada kompetensi dasar 3.9 yaitu menganalisis isi dan kebahasaan novel dan kompetensi dasar 4.9 yaitu merancang novel atau novelet dengan memerhatikan isi dan kebahasaan, dengan materi unsur instrinsik ekstrinsik dan unsur kebahasaan.

Berdasarkan kompetensi dasar 3.9 dan 4.9, peserta didik diharapkan dapat menemukan unsur instrinsik dan unsur ekstrinsik serta menemukan unsur kebahasaan. Novel Gentayangan Pilih Sendiri Petualangan Sepatu Merahmu karya Intan Paramaditha dapat dijadikan sebagai alternatif bahan ajar sastra untuk tingkat SMA kelas XII semester gasal dengan materi pembelajaran unsur instrinsik, ekstrinsik, dan unsur kebahasaan. Dalam Silabus Mata Pelajaran Bahasa Indonesia SekolahMenengahAtas/Madrasah Aliyah/Menengah Kejuruan/Madrasah Aliyah Kejuruan (SMA/MA/SMK/MAK) Kurikulum 2013 Revisi 2019.

\section{SIMPULAN}

Berdasarkan analisis yang telah dilakukan, penelitian ini menghasilkan kesimpulan bahwa novel Gentayangan Pilih Sendiri Petualangan Sepatu Merahmu karya Intan Paramaditha memiliki kesesuaian dengan kriteria pemilihan bahan ajar sastra yang dapat dijadikan sebagai alternatif bahan ajar sastra di SMA. Novel Gentayangan Pilih Sendiri Petualangan Sepatu Merahmu karya Intan Paramaditha dapat dijadikan sebagai alternatif bahan ajar sastra di SMA. Novel tersebut sesuai dengan tiga aspek kriteria pemilihan bahan ajar sastra menurut B. Rahmanto yaitu bahasa yang digunakan, psikologi, dan latar belakang budaya.Novel Gentayangan Pilih Sendiri Petualangan Sepatu Merahmu karya Intan Paramaditha memiliki bahasa yang mudah dipahami. Novel tersebut sesuai dengan usia peserta didik yaitu mulai dari 16 tahun, bahan pengajaran novel yang disajikan mengandung permasalahan hidup dan persoalan nilai-nilai hidup yang sesuai dengan kehidupan nyata.

\section{DAFTAR PUSTAKA}

Hasriyati (2016) 'Analisis Fakta Cerita dalam Novel Sayang Tanah Ibu Cinta Kita Karya Ismail Maimun', Jurnal Bastra, 1(2), p. 8. 
Juliana, S. and Sri Suryana Dinar dan Marwati (2019) 'Fakta Cerita dalam Cerita Rakyat Tolaki Randa Wula'a', 4(3), pp. 415-429.

Majid, A. (2014) Strategi Pembelajaran. Bandung: Remaja Rosdakarya.

Nurgiyantoro, B. (2013) Teori Pengkajian Fiksi. Yogyakarta: Gajah Mada Universitiy Press.

Paramaditha, I. (2017) Gentayangan Pilih Sendiri Petualangan Sepatu Merahmu. Jakarta: Gramedia Pustaka Utama.

Rahmanto (2004) Metode Pengajaran Sastra. Yogyakarta: Kanisius.

Wulandari, D. (2017) 'Fakta Cerita Dalam Novel Ayah Karya Andrea Hirata dan Implikasinya dalam Pembelajaran Sastra di SMA'. Skripsi. Lampung: Universitas Negeri Lampung 